\title{
Uso de malla mixta en cavidad abdominal contaminada. Modelo experimental en ratas Wistar
}

\author{
Flores-Álvarez Efrén*, Posadas-Ramírez Luis Ángel**, Gudiño-Amezcua Luis Manuel ***, \\ de la Torre González José ***
}

\begin{tabular}{|c|c|}
\hline 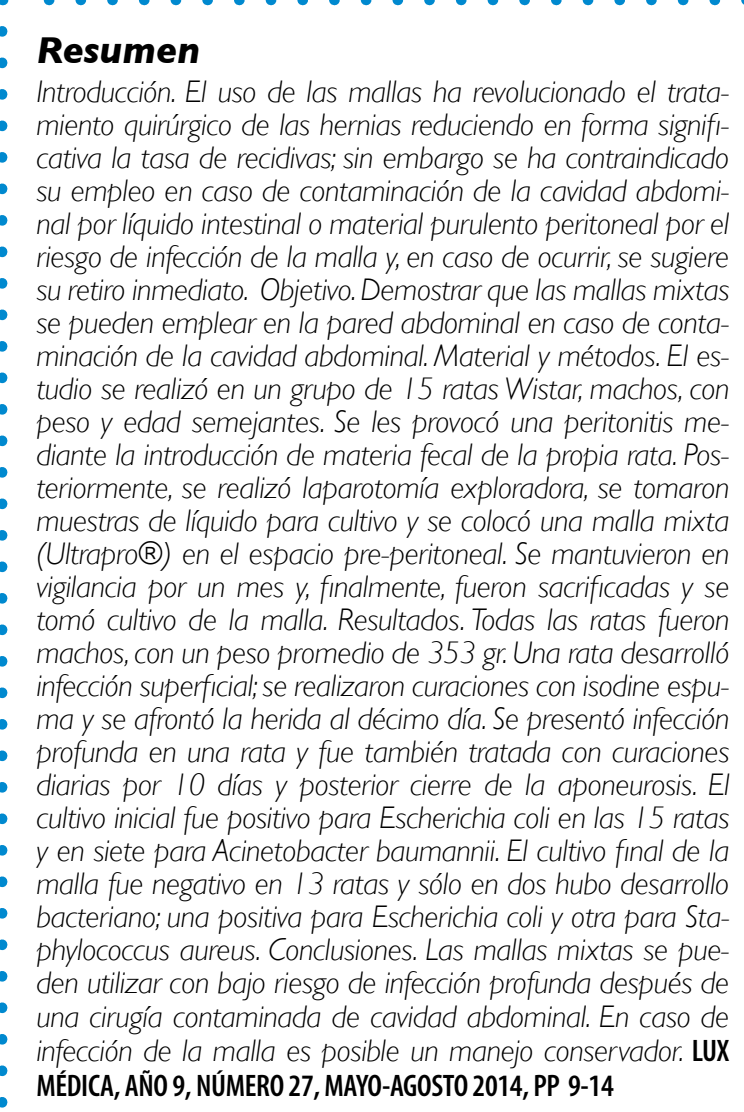 & 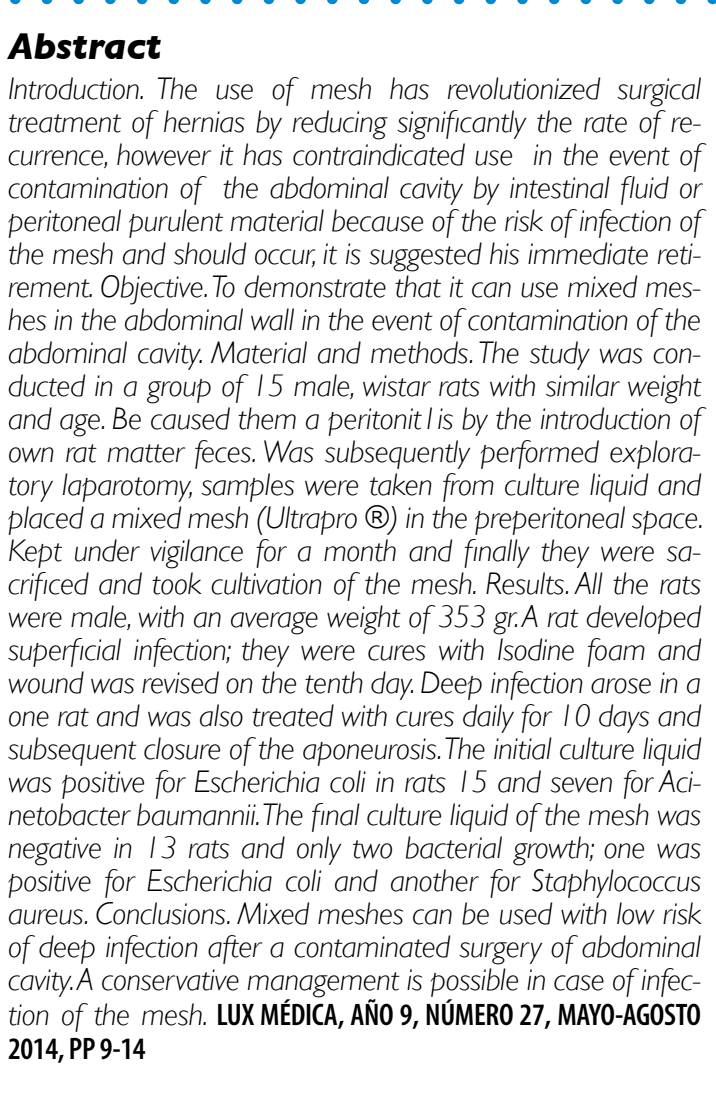 \\
\hline Palabras clave: malla, peritonitis, cultivo bacteriano, & Key words: peritonitis, mesh, Wistar rats, bacterial culture. \\
\hline
\end{tabular}

* Maestro en Ciencias. Cirujano General y Oncólogo. Profesor Titular de Posgrado en Cirugía General. Centenario Hospital Miguel Hidalgo

** Residente de Cirugía General. Centenario Hospital Miguel Hidalgo.

*** Cirujano General. Investigador Asociado. Centenario Hospital Miguel Hidalgo.

Fecha de recibido: 26 de mayo 2014

Fecha de aceptado: 26 de junio 2014

Correspondencia: MCM Efrén Flores Álvarez. Departamento de Enseñanza del Centenario Hospital Miquel Hidalgo. Calle Galeana Sur 465, Colonia Obraje. CP 20230, Aguascalientes, Ags., México. Teléfono 01(449) 9946720 Correo electrónico efflorez@hotmail.com 


\section{Introducción}

El uso de materiales protésicos en la pared abdominal inicia con la introducción de las mallas de polipropileno en 1950, desde entonces los cirujanos generales han utilizado las mallas sintéticas para el tratamiento de todo tipo de defectos herniarios de la pared abdominal. ${ }^{1}$

La reparación de hernias incisionales puede realizarse por cierre primario del defecto de la pared abdominal suturando los límites de éste y por medio de una malla protésica implantada en el defecto abdominal. Resultados recientes de un ensayo clínico demuestran que el uso del material protésico reduce la tasa de recurrencias de la hernia después de la reparación hasta $31 \%$ de los pacientes a 10 años de seguimiento. ${ }^{2}$

Si bien, la presencia de una prótesis de cualquier tipo utilizada en la reparación herniaria no favorece per se la aparición de infecciones, se calcula que la frecuencia de infecciones de herida y prótesis, de acuerdo con la literatura mundial, representa un promedio de 3-4\% para la hernias inguinales y de $8-14 \%$ para las hernias incisionales, con rangos muy amplios que dependen, entre otras cosas, de la calidad de las medidas de asepsia y antisepsia utilizadas. ${ }^{3}$

La enseñanza quirúrgica clásica contraindica el uso de material protésico en hernias encarceladas y/o estranguladas, por temor a la infección de la malla. En consecuencia, los beneficios de la reparación con malla se han limitado a los pacientes con hernias no complicadas, reparadas en forma electiva. Esta práctica condiciona que los pacientes con hernias complicadas y aquellos que se operan en forma urgente sean excluidos de los beneficios que brinda el empleo de material protésico. No existe un consenso sobre el uso de materiales protésicos en una cirugía contaminada por una cavidad abdominal séptica, ni sobre el tipo de material más apto para ser utilizado, ya que los estudios sobre dicho tema siguen siendo controversiales. ${ }^{4}$

El objetivo de este trabajo fue demostrar que las mallas mixtas se pueden utilizar con seguridad en el cierre primario después de una cirugía contaminada de la cavidad abdominal.

\section{| | | | | | | | | | | | | | | | | | | | | | | | | | | | | | | | | | | | | | | | | | | | | | | | | | | | | | | | | | | | | | | | | | | | | | | | | | | | | | | | | | | | | | | | | | | | | | | | | | || ||}

\section{Material y métodos}

El estudio fue realizado en las instalaciones del laboratorio experimental de la Universidad Autónoma de Aguascalientes. Previa aprobación por el Comité Interno para el Cuidado y Uso de Animales de Laboratorio de la Universidad Autónoma de Aguascalientes y de acuerdo a la Norma Oficial Mexicana NOM-062-200-1999. Se emplearon 15 ratas wistar, sanas, con peso y edad similares. La técnica anestésica utilizada en todas las ratas fue con éter a dosis respuesta, implementando una mascarilla especial para ratas. Se introdujeron a la cavidad peritoneal $5 \mathrm{ml}$. de materia fecal de la propia rata diluida en agua. Después de 6 hrs. se indujo nuevamente a la rata con éter y se administraron: ceftriaxona a 50 $\mathrm{mg} / \mathrm{kg} /$ dosis vía intramuscular; metronidazol a 30mg/ $/ \mathrm{kg} /$ dosis vía intramuscular y 
ketorolaco a $0.5 \mathrm{mg} / \mathrm{kg} /$ dosis vía intramuscular. Finalmente, se inyectó pentobarbital a $30 \mathrm{mg} / \mathrm{kg}$ vía intraperitoneal.

Una vez anestesiada la rata se procedió a fijarla con clips a la mesa de exploración, se realizó tricotomía y asepsia de pared con isodine espuma. Se abordó el abdomen por medio de una incisión media supra e infra umbilical, se procedió a eviscerar la cavidad abdominal y se tomaron muestras de líquido del hueco pélvico para cultivo. Una vez realizado el secado de la cavidad con gasas, se introdujeron las vísceras abdominales y se creó un espacio preperitoneal para la colocación de la malla mixta (Ultrapro®). Se cerró el espacio preperitoneal con vicryl 3-0, músculos y aponeurosis anterior en un solo plano con vicryl 3-0 y por último, la piel con surgete continuo con prolene 3-0. Se le permitió a la rata una dieta a libre demanda después de la recuperación anestésica.

Se mantuvieron en vigilancia estrecha por un mes, inspeccionando particularmente datos de infección macroscópica en el sitio quirúrgico. Cuando se presentó alguna infección, se dio manejo con curaciones utilizando Isodine ${ }^{\circledR}$ espuma. Al término de un mes, las ratas fueron sacrificadas y se realizó una nueva laparotomía exploradora para retirar la malla y enviarla a cultivo.

\section{| | | | | | | | | | | | | | | | | | | | | | | | | | | | | | | | | | | | | | | | | | | | | | | | | | | | | | | | | | | | | | | | | | | | | | | | | | | | | | | | | | | | | | | | | | | | | | | | || ||}

\section{Resultados}

El grupo de estudio estuvo formado por 15 ratas, todas del sexo masculino, con una mediana de peso de 350 gr., rango entre 315 y $400 \mathrm{gr}$. Una de las 15 ratas desarrolló infección superficial, la cual únicamente involucró piel y tejido celular subcutáneo, sin exposición del material protésico y se caracterizó por el drenaje de exudado seropurulento por la herida quirúrgica. Después de diez días de manejo con curaciones a base de isodine espuma se realizó el cierre de la herida quirúrgica. El cultivo de la malla de la rata con infección superficial resultó negativo para el desarrollo de colonias bacterianas.

Se presentó infección profunda en sólo en una de las ratas. Dicho evento fue definido como la exposición del material protésico a través de la herida quirúrgica, asociada a una dehiscencia de la aponeurosis y la presencia de exudado purulento. De la misma forma que en la infección superficial fue tratada con curaciones diarias con isodine espuma y cierre de la aponeurosis y la piel a los 10 días. El cultivo de dicha malla fue positivo.

El cultivo inicial de la muestra de la cavidad abdominal tomada previo a la colocación de la malla fue positivo para Escherichia coli en el $100 \%(n=15)$ de las ratas y el $47 \%(n=7)$ desarrollaron Acinetobacter baumannii.

En el cultivo final, a los 5 días de incubación se encontró que el $86 \%(n=13)$ no presentaban desarrollo bacteriano y solo en dos $(13 \%)$ se obtuvo un cultivo positivo, uno para Escherichia coli y otro para Staphylococcus aureus. Solo una rata desarrolló infección profunda, en ella tanto el cultivo inicial como final fueron positivos para Escherichia coli.

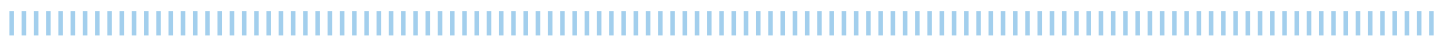

\section{Discusión}

La introducción de las mallas en el manejo de las hernias de la pared abdominal ha revolucionado el tratamiento quirúrgico mediante la introducción del concepto de reparación sin tensión. En varios estudios se ha demostrado que el uso de las mallas en la reparación de las hernias de la pared 
abdominal se asocia con una tasa de recurrencia hasta diez veces menor. ${ }^{4,5}$ El seguimiento que realizamos en nuestro estudio tuvo un periodo muy corto para poder evaluar el desarrollo de recidivas.

Tradicionalmente se ha contraindicado el uso de mallas en la reparación de hernias complicadas debido al temor al desarrollo de infección del material protésico. Dicha contraindicación incluye el tratamiento de las hernias estranguladas por el proceso inflamatorio asociado a la presencia de áreas isquémicas en el tejido comprometido dentro del saco herniario. Diferentes tipos de mallas de polipropileno han sido probadas en escenarios experimentales en animales en presencia de infección o contaminación. Díaz-Godoy y colaboradores ${ }^{6}$ demostraron en un modelo experimental en conejos que las mallas más ligeras y con un mayor tamaño de los poros se asocian a una menor infección.

Para nuestro estudio decidimos utilizar la malla Ultrapro ${ }^{\circledR}$, la cual es una malla monofilamento de baja densidad parcialmente absorbible compuesta por dos partes igual de polipropileno no absorbible y poliglecaprone absorbible, ambos monofilamentos de estos materiales se entrelazan para formar la malla resultando en un material protésico ligero y de amplia porosidad. La estructura y remanente de esta malla están óptimamente diseñados para soportar los esfuerzos fisiológicos a los que se someta la pared abdominal. Esta malla también tiene excelente manejabilidad ya que las fibras del poliglecaprone suavizan la estructura de la malla y mejoran su adaptabilidad durante la cirugía, lo que permite que pueda ser recortada y adaptada a la forma requerida, sin perder la seguridad. La parte de polipropileno de la malla provee una elasticidad multidireccional similar a la pared abdominal, adaptándose muy bien a la anatomía.

La infección de una herida quirúrgica que involucra a la prótesis utilizada para la reparación de una hernia inguinal o inci- sional, representa un evento indeseable en la adecuada evolución de nuestro procedimiento y por ende para el paciente, tal como sucede en cualquier procedimiento quirúrgico, independientemente de su grado de complejidad o de la región que se comprometa. ${ }^{3}$ Se calcula que la frecuencia de infecciones se presenta en el 3-4\% de las hernias inguinales y en $8-14 \%$ para las hernias incisionales, con rangos amplios que dependen, entre otras cosas, del ambiente hospitalario donde se realice.

Las ratas de nuestro estudio presentaron una frecuencia de infección de la malla de apenas el $6 \%$. Se acepta que a pesar de los mejores esfuerzos del equipo quirúrgico, las bacterias van a entrar a la herida, por lo que los esfuerzos deben estar dirigidos a impedir la adherencia y su reproducción en la malla. Las estrategias para reducir la tasa de infección se centran en una técnica de asepsia y antisepsia adecuadas, reducir al mínimo la cantidad de tejido inerte en la herida, utilizar electrocauterio, utilizar la mínima cantidad de suturas posibles y desbridar al final de la cirugía todos los tejidos que parezcan desvitalizados. ${ }^{7,8}$ Así mismo se han utilizado sustancias tópicas para impedir la adhesión de bacterias al material protésico, tales como las sales de plata, vancomicina, gentamicina, ciprofloxacino y otros antibióticos. Actualmente se trabaja en sustancias antisépticas que reduzcan la adhesión de las bacterias a la malla y vacunas que sean capaces de bloquearla..$^{9,10}$ En nuestro estudio, utilizamos únicamente profilaxis antibiótica a base de ceftriaxona y metronidazol, administradas una hora antes del procedimiento quirúrgico, tal como se emplea en la práctica clínica.

El manejo recomendado en caso de que se presente infección de la herida y malla es el retiro del material protésico. Existe evidencia reciente de que el manejo conservador de las heridas quirúrgicas infectadas con la presencia de una malla, evolucionan hacia el éxito en un porcentaje de 50 al 70\% de los casos sin la necesidad de 
retirar el material protésico. Hay materiales que definitivamente toleran mejor un proceso infeccioso que otros, como son los materiales macroporosos y de monofilamento; y por otro lado existen los materiales que no toleran la existencia de un proceso infeccioso como los microporosos y los multifilamentosos, que aunque llegaran a superar la etapa aguda, quedaran colonizados por bacterias, por lo que la erradicación del foco séptico es prácticamente imposible. 3,11,12

La utilización de modelos animales en cirugía ha contribuido sustancialmente al progreso en el conocimiento de diversas entidades clínicas y ha permitido el desarrollo de nuevas técnicas quirúrgicas y la validación de numerosos procedimientos terapéuticos. Las diferencias existentes entre la enfermedad humana y la inducida experimentalmente en animales, tanto en los mecanismos de regulación genética como en los factores que determinan la respues- ta del organismo son sus principales limitaciones al experimentar tanto con fármacos como con procedimientos quirúrgicos, sin embargo marcan la pauta para el desarrollo e innovación de técnicas quirúrgicas que a la postre resultan ser los procedimientos de uso clínico convencional. Nuestro estudio demuestra una frecuencia baja de infección tanto de la herida quirúrgica como del material protésico empleando una malla mixta, como la Ultrapro ${ }^{\circledR}$. Además, el manejo conservador permitió rescatar la malla en la rata que se desarrollo una infección superficial. De acuerdo a estos resultados consideramos que es posible el empleo de malla para la reparación de hernias abdominales en humanos, aun en presencia de proceso inflamatorio o infeccioso, local o peritoneal y si se presenta infección en el área quirúrgica debe individualizarse el tratamiento, tendiendo siempre en lo posible a la preservación de la malla.

\section{Conclusiones}

Las mallas mixtas se pueden utilizar con bajo riesgo de infección profunda después de una cirugía contaminada de la cavidad abdominal. En caso de infección de la malla es posible un manejo conservador.

\section{Bibliografía}

1. Flores-Álvarez $E$, Vázquez-Urtiz $O$, Rivera-Barragán V. El cirujano y la malla ideal. Biocompatibilidad de las mallas quirúrgicas. Perspectiva 2004;29:22-24.

2. Burger JW, Luijendijk RW, Hop WC, et al. Longterm follow-up of incisional hernia, Ann Surg 2004; 240;578-583

3. Mayagoitia-González JL. Infección de la malla: Un problema que no se resuelve. Cir Gen 2011; 33 (1):43-45

4. Luijendijk RW, Hop WC, van den Tol MP, et al. A comparison of suture repair with mesh repair for incisional hernia. N Engl J Med 2000;343:392-8.

5. Abdel-Baki NA, Bessa SS, Abdel-Razek AH. Comparison of prosthetic mesh repair and tissue repair in the emergency management of incarcerated para-umbilical hernia: a prospective randomized study. Hernia 2007;11:163-167.

6. Díaz-Godoy A, García-Uren MA, López-Monclís J, Vega-Ruíz V. Searching for the best polypropylene mesh to be used in bowel contamination. Hernia 2011;15:173-179.

7. Campanelli G, Nicolosi FM, Pettinari D, Avesani EC. Prosthetic repair, intestinal resection, and potentially contaminated areas: safe and feasible? Hernia 2004;8:190-192.

8. Kelly $M E$, Behrman SW. The safety and efficacy of prosthetic hernia repair in clean-contaminated and contaminated wounds. Am Surg 2002;68:524-528.

9. Bessa SS, Abdel-Razek AH. Results of prosthetic mesh repair in the emergency management of the acutely 


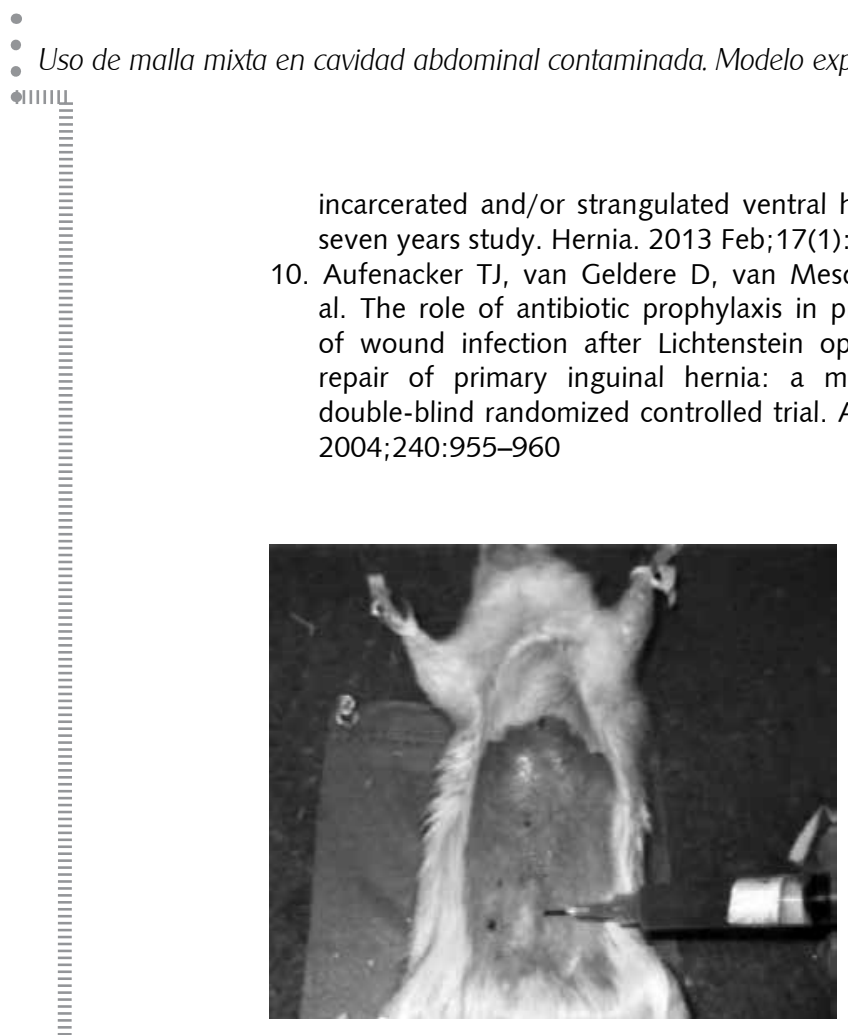

Figura 1. Inyección de materia fecal en la cavidad abdominal.
11. Deysine M. Pathophysiology, prevention and management of prosthetic infections in hernia surgery. Surg Clin North Am 1998; 78: 1105-15.

12. Ueda J, Nomura $T$, Sasaki J, Shigehara $K$, et al. Prosthetic repair of an incarcerated groin hernia with small intestinal resection. Surg Today 2012;42:359362.

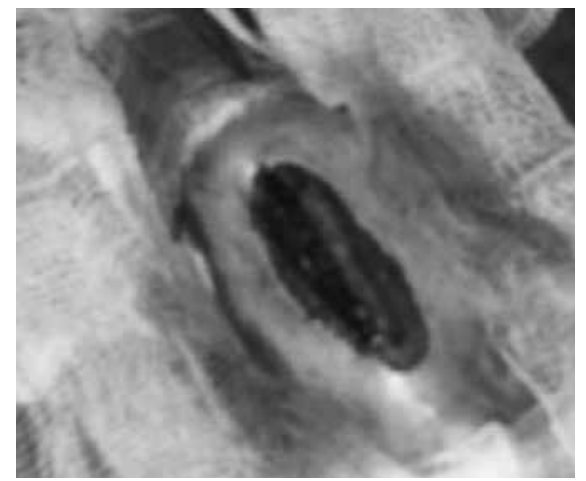

Figura 2. Tricotomía, asepsia, antisepsia y laparotomía exploradora.

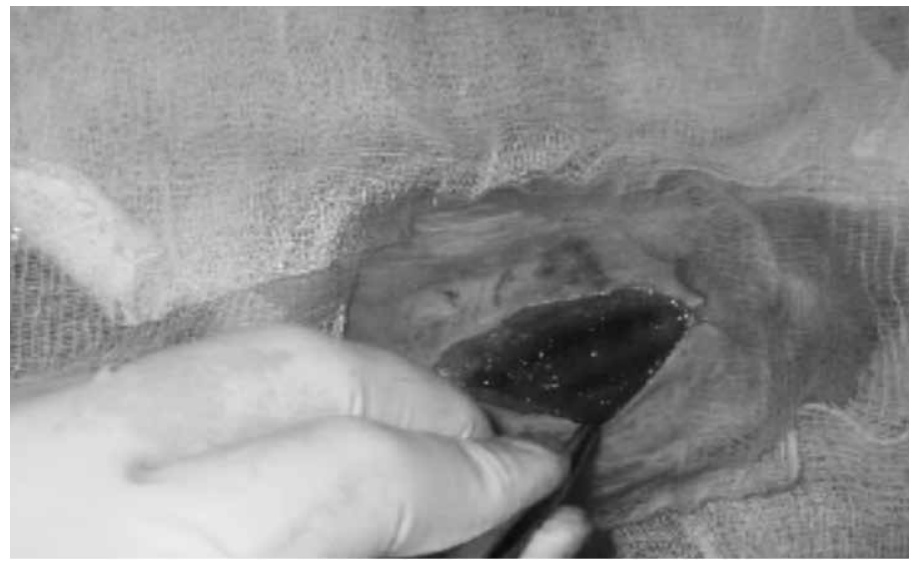

Figura 3. Colación de malla en el espacio preperitoneal.

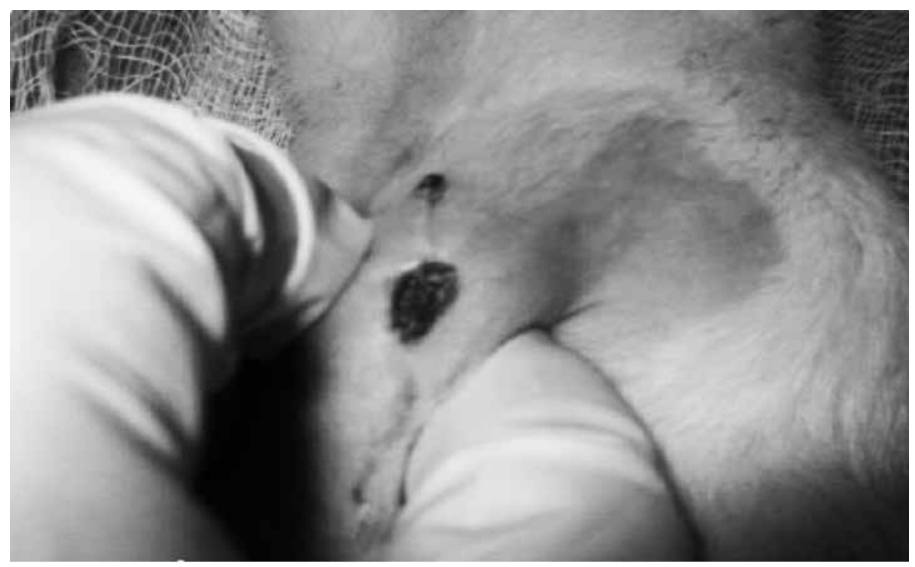

Figura 4. Infección de herida quirúrgica. 